Artikel Penelitian

\title{
Aktivitas Antimalaria Ekstrak Kasar Etanol dan Fraksi n-Heksana Rumput Bambu (Lophatherum gracile B.) secara in Vitro
}

\author{
Ella Wulandari ${ }^{1}$, Dewi Yuliani ${ }^{1}$, Elok Kamilah Hayati ${ }^{*}$, Roihatul Muti'ah²
}

1Jurusan Kimia, Fakultas Sains dan Teknologi, Universitas Maulana Malik Ibrahim, Malang, Indonesia, 65145

2Jurusan Farmasi, Fakultas Sains dan Teknologi, Universitas Maulana Malik Ibrahim, Malang, Indonesia, 65145

INFO ARTIKEL

\section{Riwayat Artikel}

Direvisi 14 Oktober 2018

Diterima 11 November 2018

Tersedia online 30 November 2018

* Email penulis korespondensi:

eloksunardji@yahoo.com

\section{ABSTRAK}

Malaria is a disease caused by infectious parasite Plasmodium falciparum and can be transmitted through mosquito bite. The aim of this research was to study antimalarial activity in vitro on crude ethanol extract and n-hexane fraction of bamboo grass (Lophatherum gracile B.). Extraction was carried out by ethanol $80 \%$ solvent and fractionation was conducted by $n$-hexane. Determination of antimalarial activity was subjected to $P$. falciparum strain 3D7. According to phytochemical test, crude ethanol extract contained tannin and terpenoid, whilst n-hexane fraction contained tannin and steroid. The capability of crude ethanol extract and $n$-hexane fraction to inhibit $P$. falciparum was represented by $\mathrm{IC}_{50}$ value. The value of both samples respectively was 12.49 and $61.49 \mu \mathrm{g} / \mathrm{mL}$. Identification based on LC-MS (liquid chromatography-mass spectrometry), nhexane fraction shown the presence of tannin and steroid compounds.

Keywords: Bamboo grass (Lophatherum gracile B), Plasmodium falciparum, antimalaria, LC-MS

Malaria merupakan penyakit yang disebabkan oleh infeksi parasit Plasmodium falciparum yang dapat ditularkan melalui gigitan nyamuk. Penelitian ini bertujuan untuk mengetahui aktivitas antimalaria secara in vitro pada ekstrak kasar etanol dan fraksi n-heksana rumput bambu (Lophatherum gracile B.). Proses ekstraksi dilakukan dengan pelarut etanol $80 \%$ dan fraksinasi dengan $n$-heksana. Uji aktivitas antimalaria dilakukan pada parasit $P$. falciparum strain 3D7. Hasil uji fitokimia menunjukkan ekstrak etanol mengandung tanin dan terpenoid, sedangkan fraksi n-heksana mengandung tanin dan steroid. Kemampuan ekstrak etanol dan fraksi n-heksana dalam menghambat parasit $P$. falciparum menghasilkan nilai $\mathrm{IC}_{50}$ masing-masing sebesar 12,49 dan $61,49 \mu \mathrm{g} / \mathrm{mL}$. Identifikasi senyawa dengan KC-SM (kromatografi cair-spektrometri massa) pada fraksi n-heksana menunjukkan adanya senyawa tanin dan steroid.

Kata Kunci: Rumput bambu (Lophatherum gracile B.), Plasmodium falciparum, antimalaria, KC-SM 


\section{Pendahuluan}

Malaria merupakan penyakit yang penyebarannya melalui gigitan nyamuk yang sudah terinfeksi suatu parasit. Parasit yang yang menyebabkan malaria salah satunya adalah Plasmodium falciparum [1]. Malaria menjadi salah satu masalah kesehatan di Indonesia yang dapat menyebabkan kematian terutama pada bayi, balita, dan ibu hamil. Penyakit ini juga dapat mengakibatkan anemia dan menurunkan produktivitas kerja [2].

Salah satu kendala dalam penangganan malaria adalah adanya resistensi terhadap obat antimalaria (klorokuin) [3]. Timbulnya resistensi $P$. falciparum terhadap klorokuin mendorong para peneliti untuk mencari obat antimalaria baru yang dapat menggantikan obat antimalaria lama yang sudah tidak efekltif. Salah satu usaha yang dilakukan adalah dengan melakukan penelitian terhadap obat-obat tradisional yang berasal dari tumbuh-tumbuhan yang dipercayai masyarakat dapat menyembuhkan penyakit [4].

Bahan kimia sintetik yang terkandung dalam obat modern memiliki dampak yang kurang baik dalam mengobati penyakit dibandingkan dengan obat herbal yang berasal dari bahan alam. Obat modern umumnya memiliki efek samping yang berbahaya bagi tubuh [5]. Hal tersebut mendorong dilakukan penelitian ilmiah di bidang pengobatan herbal yang berasal dari bahan alam, salah satunya adalah tanaman rumput bambu (Lophatherum gracile B.).

Rumput bambu merupakan tanaman gulma yang mudah tumbuh di tempat rindang. Kusumawati dkk. menyatakan bahwa rumput bambu mengandung flavonoid pada daun dan steroid atau triterpenoid pada akar [6]. Identifikasi yang dilakukan Jing dkk. [7] menemukan adanya 14 kandungan senyawa metabolit sekunder pada daun rumput bambu selain flavonoid dan triterpenoid. Tanaman ini mengandung senyawa tanin yang diketahui mempunyai beberapa khasiat diantaranya sebagai antibakteri, antioksidan, antikanker dan antimalaria [8].

Beberapa metabolit sekunder telah terbukti bermanfaat sebagaia antimalaria adalah alkaloid, sesquiterpen, triterpenoid, dan flavonoid. Senyawa tanin, alkaloid, dan steroid pada anting-anting (Acalypha indica L.) menunjukkan kemampuan menghambat pertumbuhan $P$. berghie pada dosis 0,$01 ; 0,1$ dan $1 \mathrm{mg} / \mathrm{g}$ BB masing-masing sebesar 87,19 ; 84,90 dan 90,94\% [9]. Penelitian Rohmaniyah [10] menyatakan rumput bambu mengandung senyawa tanin dan steroid. Ariantari dkk. [11] menyebutkan ekstrak metanol daun murbei mengandung flavonoid dan triterpenoid dimana senyawa tersebut digunakan sebagai antimalaria pada uji in vitro terhadap $P$. falciparum $3 \mathrm{D} 7$ dengan nilai $I \mathrm{C}_{50}$ sebesar $0,02 \mathrm{ug} / \mathrm{mL}$. Kandungan senyawa tanin pada anting-anting dilaporkan mempunyai aktivitas antimalaria secara in vivo [12].

Pengujian antimalaria pada penelitian ini dilakukan secara in vitro dengan metode Trager \& Jensen [13] pada parasit $P$. falciparum strain 3D7. Penelitian ini bertujuan untuk mengetahui persen penghambat parasit malaria dengan menghitung $\mathrm{IC}_{50}$ pada ekstrak kasar etanol dan fraksi n-heksana rumput bambu.

\section{Bahan dan Metode}

\subsection{Bahan}

Bahan utama penelitian ini adalah tanaman rumput bambu yang berasal dari daerah Malang. Parasit Plasmodium falciparum strain 3D7 digunakan sebagai hewan uji. Bahan kimia yang digunakan yaitu etanol 80\%, n-heksana, DMSO, methanol, gas nitrogen dan larutan pewarna Giemsa 20\%.

\subsection{Ekstraksi Senyawa Aktif}

Sebanyak 200 gram serbuk rumput bambu dimaserasi dengan $800 \mathrm{~mL}$ pelarut etanol selama 24 jam. Kemudian, sampel tersebut dishaker dengan kecepatan $130 \mathrm{rpm}$ selama 3 jam. Selanjutnya, sampel disaring dan ampas yang diperoleh dimaserasi kembali dengan pelarut yang sama sampai filtrat yang diperoleh berwarna lebih bening. Filtrat yang diperoleh disaring menggunakan vacuum Buchner dan dipekatkan dengan rotary evaporator dan dialiri gas nitrogen.

Ekstrak pekat etanol sebanyak 20 gram dilarutkan dalam $100 \mathrm{~mL}$ pelarut etanol. Selanjutnya, ekstrak etanol yang sudah diuapkan dipartisi dengan $50 \mathrm{~mL}$-heksana dengan pengulangan sebanyak 5 kali. Fraksi n-heksana dikumpulkan dan ditimbang untuk ditentukan nilai randemennya. Penentuan persen rendemen dilakukan membandingkan berat ekstrak dengan berat sampel.

\subsection{Uji Fitokimia}

Penentuan kandungan senyawa aktif pada ekstrak pekat etanol dan fraksi n-heksana rumput bambu dilakukan dengan uji reagen. Uji fitokimia yang dilakukan pada penelitian ini meliputi uji flavonoid, alkaloid, saponin, triterpenoid, steroid, dan tanin $[14,15,16]$. 


\subsection{Uji Antimalaria secara in Vitro}

Pengujian ini dilakukan berdasarkan metode dasar yang dikembangkan oleh Trager \& Jensen [13]. Kultur $P$. falciparum dilakukan proses thawing dan pembiakan. Sampel dilarutkan dalam DMSO dengan variasi konsentrasi 0,01; 0,$1 ; 1 ; 10$ dan $100 \mu \mathrm{L} / \mathrm{mL}$. Campuran sampel dengan suspensi parasit dimasukkan dalam candle jar dan diinkubasi selama 48 jam pada suhu $37^{\circ} \mathrm{C}$.

Setelah proses inkubasi selesai dibuat sediaan hapusan darah tipis. Selanjutnya, sediaan dikeringkan pada suhu kamar, difiksasi dengan metanol, dan diwarnai dengan Giemsa 15\% setelah sediaan kering. Sediaan hapusan darah tipis diperiksa menggunakan mikroskop cahaya perbesaran 1000x. Eritrosit terinfeksi $P$. falciparum dihitung untuk menentukan tingkat parasitemia (Persamaan 1) dan persen hambatan (Persamaan 2).

$$
\begin{gathered}
\text { Parasitemia }(\%)=\frac{\text { Eritrosit yang terinfeksi parasit }}{\text { Total eritrosit (1000 eritrosit) }} \times 100 \% \\
\text { Hambatan }(\%)=100 \%-\left(\frac{\text { Rata-rata parasitemia yang diperlakukan }}{\text { Rata-rata parasitemia kontrol }} \times 100 \%\right)
\end{gathered}
$$

\subsection{Identifikasi dengan LC-MS}

Fraksi n-heksana diidentifikasi menggunakan HPLC Alliance 2695 (Waters). Adapun spesifikasi HLPC adalah photodiode-array (PDA) detector 2996 (Waters), kolom sunfire C18; $5 \mathrm{~cm} ; 4,6 \mathrm{~mm} \mathrm{ID} \mathrm{x} 150 \mathrm{~mm}$ (Waters); suhu kolom $300^{\circ} \mathrm{C}$; kecepatan alir $1 \mathrm{~mL} / \mathrm{min}$, fasa gerak campuran $\mathrm{H}_{2} \mathrm{O}$ (HPLC grade) dan asam format, serta asetonitril; metode $\mathrm{HPLC}$ gradient $30 \% \mathrm{H}_{2} \mathrm{O}$ dan $0,1 \%$ asam format; $70 \%$ asetonitril, panjang gelombang 210, 410, dan $435 \mathrm{~nm}$. HPLC/ESI/Q-ToF/MS dilhubungkan dengan sistem HPLC dengan sumber ion ESI. Kondisi spektoskopi massa adalah alat LCT Premier XE (Waters); Analyser MS: TOF (Time of Flight) dengan electrosprayer modus positif (ES+) dan negatif (ES-) dari m/z 100 sampai m/z 2000; capillary voltage 1800 V; sample cone voltage $60 \mathrm{~V}$; disolvation temperature 300\%; source temperature $100^{\circ} \mathrm{C}$; dan disolvation gas flow $600 \mathrm{~L} /$ hour.

\section{Hasil dan Pembahasan}

\subsection{Ekstrak Senyawa Aktif}

Sampel serbuk rumput bambu sebanyak 200 gram dimaserasi dengan pelarut etanol $80 \%$ selama 24 jam dimana proses ini dilakukan dengan 3 kali pengulangan. Hasil ekstrak pekat yang diperoleh berwarna hijau tua dengan berat 21,58 gram dan menghasilkan rendemen sebesar 10,79\%. Ekstrak pekat difraksinasi dengan pelarut $n$-heksana dan diperoleh berat sebesar 3,35 gram dengan rendemen sebesar $22,23 \%$.

\subsection{Uji Fitokimia}

Uji fitokimia bertujuan mengetahui kandungan senyawa aktif yang terdapat dalam sampel berdasarkan warna yang terbentuk. Uji ini dilakukan pada ekstrak kasar etanol dan fraksi $n$-heksana rumput bambu. Berdasarkan uji fitokimia, ekstrak etanol mengandung tanin dan terpenoid, sedangkan fraksi n-heksana mengandung tanin dan steroid.

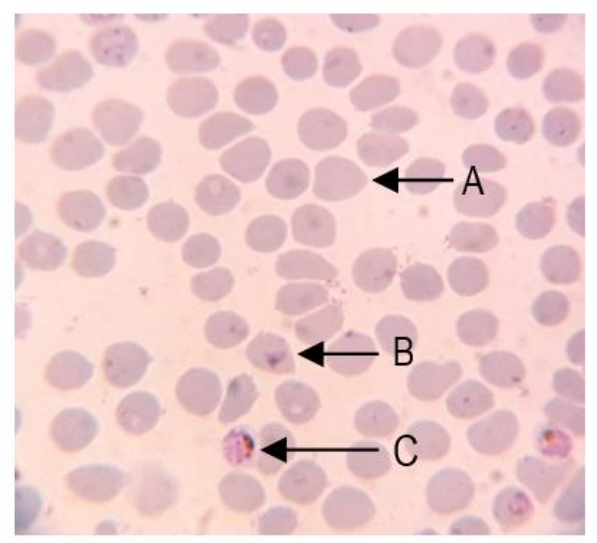

Gambar 1. (A) Eritrosit tidak terinfeksi, (B) eritrosit terinfeksi parasit dan (C) parasit dalam fase merozoit. Eritrosit diamati menggunakan mikroskop dengan perbesaran 1000x. 


\subsection{Uji Aktivitas Antimalaria}

Pengujian aktivitas antimalaria dilakukan untuk mengetahui aktivitas dari ekstrak kasar etanol dan fraksi $n$-heksana dalam menghambat $P$. falciparum strain 3D7 dengan menggunakan variasi konsentrasi 100;10;1;0,1, dan $0,01 \mu \mathrm{g} / \mathrm{mL}$. Gambar 1 menunjukkan sejumlah eritrosit yang terinfeksi dengan $P$. falciparum dan eritrosit yang lainnya tidak terinfeksi. Adanya parasit malaria ditandai dengan inti berwarna merah dan plasma berwarna biru sedangkan sel darah merah normal ditandai dengan warna merah muda.

Persen penghambatan ekstrak etanol dan fraksi n-heksana pada rumput bambu ditunjukkan pada Gambar 2. Ekstrak etanol memberikan persen penghambat sebesar 2,26; 10,66; 23,90; 39,49 dan 77,23\% pada konsentrasi 0,01; 0,1; 1; 10 dan $100 \mu \mathrm{L} / \mathrm{mL}$, secara berturut-turut. Persen penghambatan pada fraksi n-heksana lebih kecil dibandingkan pada ekstrak etanol. Pada konsentrasi 0,$01 ; 0,1 ; 1 ; 10$ dan $100 \mu \mathrm{L} / \mathrm{mL}$, presentase penghambatan fraksi $\mathrm{n}$-heksana secara berturut-turut adalah 0,$92 ; 6,15 ; 15,69 ; 25,95$ dan $58,46 \%$. Tingginya konsentrasi sampel berbanding lurus dengan tingginya persen penghambatan terhadap parasit $P$. falciparum.

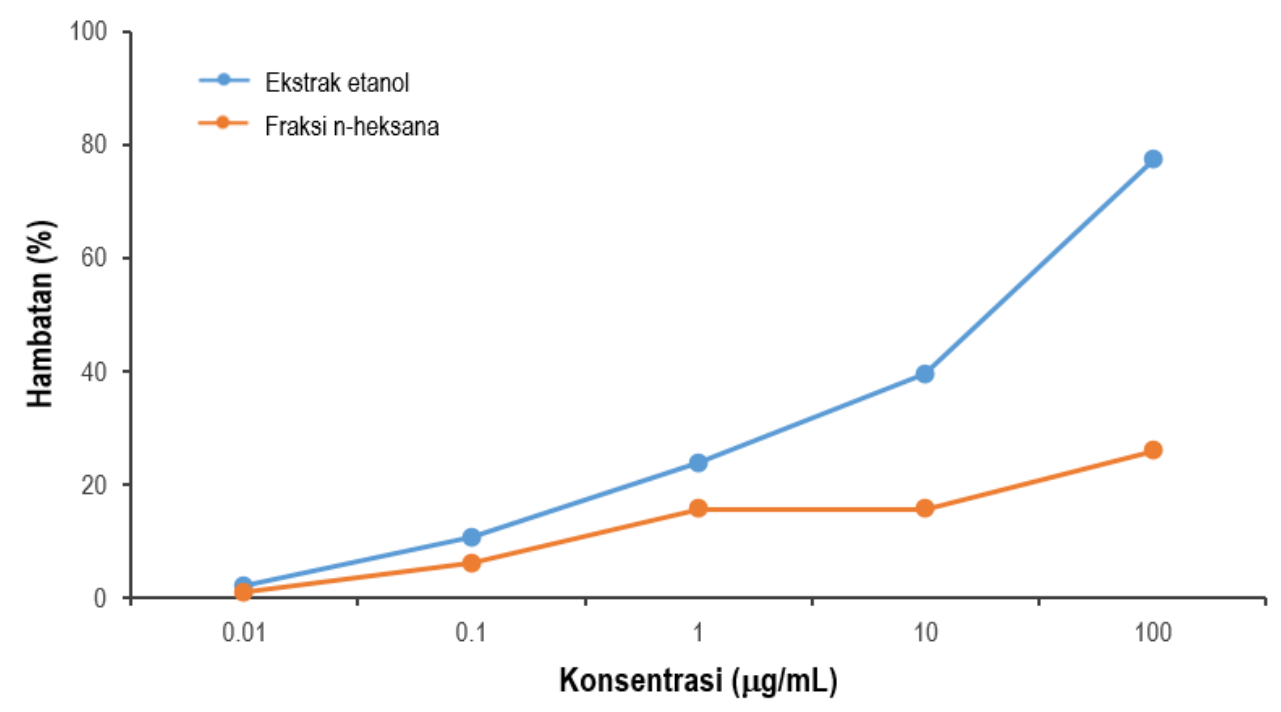

Gambar 2. Hubungan konsentrasi ekstrak etanol dan fraksi n-heksana rumput bambu terhadap persen penghambatan parasit $P$. falciparum.

Adapun nilai $\mathrm{IC}_{50}$ dari ekstrak kasar etanol dan fraksi n-heksana rumput bambu masing-masing sebesar 12,49 dan $61,46 \mu \mathrm{g} / \mathrm{mL}$. Kohler dkk. [17] menyatakan bahwa suatu ekstrak dan fraksi berpotensi sebagai antimalaria secara in vitro apabila memiliki nilai $\mathrm{IC}_{50}$ sebesar $50 \mu \mathrm{g} / \mathrm{mL}$ dan kurang dari $25 \mu \mathrm{g} / \mathrm{mL}$. Hal ini menunjukkan bahwa ekstrak rumput bambu etanol berpotensi sebagai antimalaria.

Penelitian Syafii dkk. [18] menyebutkan aktivitas antimalaria ekstrak kayu bidara laut dengan ekstrak etanol dan nheksana 3,09 dan $889,30 \mu \mathrm{g} / \mathrm{mL}$. Apabila dibandingkan dengan penelitian tersebut, nilai $\mathrm{IC}_{50}$ ekstrak etanol rumput bambu lebih kecil dibandingkan ekstrak etanol kayu bidara laut, akan tetapi fraksi $n$-heksana rumput bambu lebih besar daripada ekstrak $\mathrm{n}$-heksana kayu bidara laut. Perbedaan nilai $\mathrm{IC}_{50}$ tersebut disebabkan karena perbedaan komposisi metabolit sekunder yang terkandung pada masing-masing tanaman.

\subsection{Identifikasi Senyawa dengan LC-MS}

Hasil identifikasi LC-MS, terdapat tiga senyawa yang dapat teridentifikasi pada fraksi n-heksana rumput berdasarkan waktu retensi. Ketiga senyawa tersebut ditandai dengan tiga puncak yang masing-masing memiliki waktu retensi 5,26; 5,55 dan 5,85 menit (Gambar 3). Puncak 1 merupakan senyawa 4-metil-sigmast-22-en-3-ol golongan steroid dengan luas area 30\% dan berat molekul $\mathrm{m} / \mathrm{z} 441,2067$. Puncak 2 merupakan senyawa ellagic-acid-glucoside 2ethyl-3,4,5-trimethy tetrahydrofuran golongan tanin dengan luas area $20 \%$ dan berat molekul $\mathrm{m} / \mathrm{z} 594,3001$. Puncak 3 merupakan acid-gallic acid galloyl golongan tanin dengan luas area $100 \%$ dan berat molekul $\mathrm{m} / \mathrm{z} 623,3428$. Data spektroskopi massa terlampir pada pada supplementary file. 


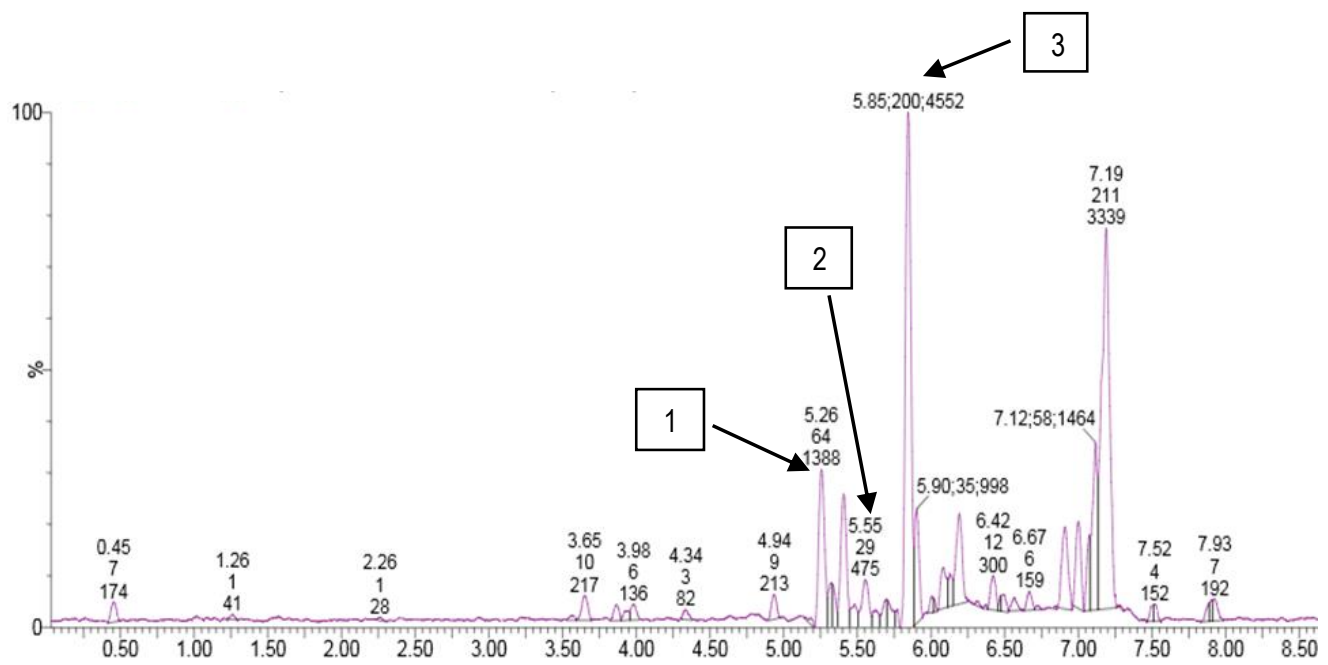

Gambar 3. Kromatogram UPLC hasil pemisahan senyawa dalam fraksi n-heksana rumput bambu.

\section{Kesimpulan}

Ekstrak kasar etanol mempunyai aktivitas antimalaria tertinggi dibandingkan fraksi n-heksana dalam menghambat parasit $P$. falcifarum strain 3D7. Nilai IC 50 ekstrak kasar etanol sebesar $12,49 \mu \mathrm{g} / \mathrm{mL}$ sedangkan fraksi n-heksana sebesar $61,47 \mu \mathrm{g} / \mathrm{mL}$. Senyawa yang terdapat dalam fraksi $\mathrm{n}$-heksana adalah golongan steroid dan tanin berdasarkan hasil identifikasi UPLC/QToF/MS/MS.

\section{Daftar Pustaka}

[1] World Health Organization, In Vitro Micro-test (Mark III) for the Assessment of the Response of Plasmodium falciparum to Chloroquine, Mefloquine, Quinine, Amodiaquine, Sulfadoxine/Pyrimethamine and Artemisinin, Division control of Tropical Disease, World Health Organization, 2008.

[2] Kementerian Kesehatan Republik Indonesia, "Epidemiologi Malaria di Indonesia," Buletin Jendela, Data dan Informasi Kesehatan, 2011.

[3] E. Tjitra, "Obat-Obat Baru Anti Malaria," Cermin Dunia Kedokteran, no. 94, pp. 16-22, 1994.

[4] Departemen Kesehatan Republik Indonesia, Pedoman Penatalaksanaan Kasus Malaria di Indonesia. Direktorat Jenderal Pengendalian Penyakit dan Penyehatan Lingkungan, 2008.

[5] I. W. Sumawinata, B. L. Bernadeta, S. Awalludin, B. Purnomo, S. Subianto, D. J. Fryauff, \& J. K. Baird, "Very High Risk of Therapeutic Failure with Chloroquine for Uncomplicated Plasmodium falciparum and $P$. vivax Malaria in Indonesian Papua," American Journal Tropical Medicine and Hygiene, vol. 68, no. 4, pp. 416-420, 2003.

[6] I. Kusumawati, W. Djatmiko, A. Rohman, H. Studiawan, \& W. Ekasari, "Eksplorasi Keanekaragaman dan Kandungan Kimia Tumbuhan Obat di Hutan Tropis Gunung Arjuna," Jurnal Bahan Alam Indonesia, vol. 2, no. 3, pp. 100-104, 2003.

[7] Z. Jing, W. Ying, X-Q, Zhang, Q-W. Zhang, \& W-C. Ye, "Chemical Constituents from the Leaves of Lophatherum gracile," Chinese Journal of Natural Medicines, vol. 7, no. 6, pp. 428-431, 2009.

[8] Y. Desmiaty, H. Ratih, M. A. Dewi, \& R. Agustin, "Penentuan Jumlah Tanin Total pada Daun Jati Belanda (Guazuma ulmifolia Lamk) dan Daun Sambang Darah (Excoecaria bicolor Hassk.) secara Kolorimetri dengan Pereaksi Biru Prusia," Ortocarpus, vol. 8, pp. 106-109, 2008.

[9] E. K. Hayati, A. Jannah, \& R. Ningsih, "Identifikasi Senyawa dan Aktivitas Antimalaria in Vivo Ekstrak Etil Asetat Tanaman Anting-anting (Acalypha indica Linn)," Molekul, vol. 7, no. 1, pp. 20-32, 2012.

[10] M. Rohmaniyah, "Uji Antioksidan Ekstrak Etanol 80\% dan Fraksi Aktif Rumput Bambu (Lophatherum gracile Brogn) Menggunakan Metode DPPH serta Identifikasi Senyawa Aktif," Skripsi, Universitas Islam Negeri Maulana Malik Ibrahim, Malang, 2016.

[11] N. P. Ariantari, P. A. Vanadis, K. G. Y. Widyadana, L. Tumewu, \& A. Widyawaruyanti, "In Vitro Antimalarial Activity of Methanolic Extract of Morus alba L. Leaves against Plasmodium falciparum 3D7," In International Conference: Research and Application on Traditional Complementary and Alternative Medicine in Health Care (TCAM), 2012, pp. 133-137. 
[12] A. H. Nihaya, "Identifikasi Senyawa Ekstrak Etil Asetat Tanaman Anting-Anting (Acalypha indica Linn.) dan Uji Aktivitas Antimalaria in Vivo pada Hewan Uji," Skripsi, Universitas Islam Negeri Maulana Malik Ibrahim, Malang, 2011.

[13] W. Trager \& J. B. Jensen, "Human Malaria Parasites in Continuous Culture," Science, vol. 193, no. 4254, pp. 673$675,1976$.

[14] J. B. Harborne, Metode Fitokimia Penuntun Cara Modern Menganalisis Tumbuhan. Bandung: ITB Press, 1987.

[15] N. Halimah,"Uji Fitokimia dan Uji Toksisitas Ekstrak Tanaman Anting-Anting (Acalypha indica Linn) terhadap Larva Udang Artemia salina Leach," Skripsi, Universitas Islam Negeri Maulana Malik Ibrahim, Malang, 2012.

[16] S. M. Lestari, "Uji Penghambatan Ekstrak Daun Sidaguri (Sida rhombifolia L.) terhadap Aktivitas Xantin Oksidase dan Identifikasi Golongan Senyawa pada Fraksi yang Aktif," Skripsi, Universitas Indonesia, Jakarta, 2012.

[17] I. Kohler, K. Jenett-Siems, K. Siems, M. A. Hernández, R. A. Ibarra, W. G. Berendsohn, U. Bienzle, \& E. Eich, "In Vitro Antiplasmodial Investigation of Medicinal Plants from El-Salvador," Zeitschrift für Naturfosrschung C, vol. 57, no. 3-4, pp. 277-281, 2002.

[18] W. Syafii, R. K. Sari, U. Cahyaningsih, \& L. N. Anisah, "Aktivitas Antimalaria Ekstrak Kayu Bidara Laut," Jurnal IImu Teknologi Kayu Tropis, vol. 14, no. 1, pp. 1-10, 2016. 